\title{
THE INTRAVENOUS INFUSION OF THE STREPTOCOCCAL FIBRINOLYTIC PRINCIPLE (STREPTOKINASE) INTO PATIENTS ${ }^{1}$
}

\author{
By WILLIAM S. TILLETT, ALAN J. JOHNSON, AND W. ROSS MCCARTY
}

\begin{abstract}
(From the Departments of Medicine and Surgery, New York University College of Medicine, and the Third Medical and Surgical Divisions of Bellevue Hospital, New York, N. Y.)
\end{abstract}

(Submitted for publication June 17, 1954; accepted October 13, 1954)

The streptococcal fibrinolytic principle (streptokinase) has been demonstrated to be an effective agent, in vivo, in patients as a means of mediating the relatively rapid liquefaction of extravascular fibrin coagulums (1). Streptokinase (referred to in this article as SK) has also been shown to be useful as a therapeutic reagent, by which massive extravascular clots may be eradicated by liquefaction and aspiration (2). These findings have received extensive confirmation. (See Footnote 12 to the list of References.)

It is the purpose of this article to describe the results of studies of the intravenous administration of SK into patients. The ultimate objective of the study is directed toward attempting to determine whether or not clots occurring within the vascular system as a result of disease may be subject to streptococcal fibrinolysis. It seemed desirable, however, to initiate the studies by making preliminary observations concerning the toxicity for patients of the currently available preparations of SK and the extent to which streptococcal fibrinolytic activity may be created within the general circulation.

In a previous report (3) intravascular clots artificially induced in the marginal ear veins of rabbits with sodium morrhuate proved to be susceptible to eradication by lysis when infusions of SK were introduced intravenously into the vein of the opposite ear. By the experimental procedure employed, the fibrinolytic system was rendered active within the circulating blood, and remained present for 6 to 12 hours depending on the amount of SK and the duration of the infusion. The intravascular clots liquefied within 3 to 7 hours of the beginning of the infusion.

1 This study was supported by grants from the $\mathrm{Na}$ tional Institute of Health, U. S. Department of Health, Education and Welfare, and Lederle Laboratory Division of the American Cyanamid Company.
In patients, the intravenous introduction of SK has proceeded with considerable caution. The amount of SK has been gradually increased beginning with doses as small as 50 units contained in $10 \mathrm{ml}$. of solution. In preparing solutions of SK for use in patients three variables have been taken into consideration: 1) Units of SK per injection, 2) concentration of SK in relation to total volume of solution; 3 ) duration of infusion.

As the amount of SK approached "therapeutic" levels, the most noteworthy toxic effects have been a pyrogenic response and depressions in blood pressure. Their occurrence and the use of drugs to counteract the untoward reactions will be subsequently described.

Of special importance has been the dosage of SK at which an effective streptococcal fibrinolytic system was created within the circulating blood of the patients.

The data contained in this article deal with the toxic effects and the measurements pertaining both to increments involved in intravascular streptococcal fibrinolysis, and also to alterations in complement and prothrombin time.

\section{MATERIALS AND METHODS}

Streptokinase. The SK was contained in Varidase 2 Varidase is a concentrated and partially purified protein preparation containing other enzymes of streptococcal origin, notably streptodornase (SD), which was present in a ratio of 4 units of SK (3) to 1 unit of SD (4). Other enzymes that may be present are hyaluronidase and ribonuclease. It is estimated that active SK constitutes about 10 per cent of the protein in Varidase.(8) It is apparent, therefore, that even though partially purified, there is a considerable amount of extraneous material present in Varidase 19 . The amount of SK is estimated as approximately 100 units per gamma of nitrogen.

$\mathrm{Up}$ to the present time only two lots of the concentrate have been employed extensively, Lot $96 \mathrm{~A}$ and Lot 333A.

2 Supplied by Lederle Laboratories, Pearl River, N. Y. 
Prepared in a dry form, each vial contained approximately 100,000 units of SK.

With each lot, the injections were initiated in very small amounts and low concentrations. The toxicities may be referable to extraneous and unknown substances present in undetermined amounts in different lots. Even though the activity of SK and the method of preparation of different lots is the same, it was not assumed that the toxicity of all lots would be comparable.

Preparation of infusions. Although different amounts of SK contained in different total volumes have been employed, in the observations reported in greatest detail in this article, 100,000 units of SK (one vial) was dissolved in $500 \mathrm{ml}$. of a saline-albumin solution to make a final concentration of 200 units of SK per $\mathrm{ml}$. The diluent was prepared by adding purified, heated, sterile human albumin 3 to physiological saline in sufficient quantity to make a 1 per cent solution. Unpublished observations have demonstrated that the activity of SK in dilute solutions is preserved in the presence of 1 per cent albumin for at least 24 hours at room temperature.

Rates of infusion. Although varying rates of infusion have been employed, the main data were derived from introducing the $500 \mathrm{ml}$. of SK solution intravenously in 4 to 5 hours, or approximately 20,000 units of SK in 80 to $100 \mathrm{ml}$. per hour. Specific variation from this infusion rate will be considered in individual protocols.

Clinical observations. During the period of the infusion, pulse, temperature and blood pressure were taken at least every 15 minutes. The symptoms, if any, were also recorded. After termination of the infusion, the observations were generally continued for 24 to 48 hours.

Pre-infusion medication. The febrile response was counteracted with amidopyrine. In an effort to control the depression in blood pressure the antihistamine Chlortrimeton Maleate was administered. The amidopyrine $(0.6 \mathrm{gm}$.) and Chlor-trimeton Maleate $(4 \mathrm{mgm}$.) were given four times a day for two days preceding the infusion and continued until 24 to 36 hours after termination of the infusion. Their effects will be subsequently described.

That drugs belonging to the antihistamic group have a pressor effect has been reported by Yonkman, Chess, Mathieson, and Hansen (5) in studies of Pyribenzamine 1.5 Since Chlor-trimeton has proved to exert the minimum of untoward side effects, it has been employed in this study.

Laboratory determinations. The tests fall into two general categories: a) Those primarily associated with the streptococcal fibrinolytic system and its activity; and b) collateral hematological tests and urine examinations.

${ }^{8}$ Normal serum albumin (human) salt-poor, U.S.P., Cutter Laboratories, Berkeley, California.

- Chlor-trimeton Maleate, brand of chlorprophenpyridamine maleate, Schering Corp., Bloomfield, New Jersey.

- Pyribenzamine Hydrochloride, Brand of Tripelennamine Hydrochloride, Ciba Pharmaceutical Products, Inc., Summit, New Jersey.
SK activity tests. The essential test for determining streptococcal fibrinolytic activity was performed as follows :

The patient's blood was drawn in a syringe washed with saline (as for a Lee-White clotting time) and the fibrinolytic activity was determined on the undiluted whole blood in vitro by adding $2 \mathrm{ml}$. of fresh venous blood to a previously siliconed, ${ }^{6}$ graduated, 10 to $15 \mathrm{ml}$. centrifuge tube (Figure 1). The rubber stopper was then inserted, with its attached wire, ${ }^{7}$ and the tube placed in a waterbath at $37.5^{\circ} \mathrm{C}$. The blood usually clotted in the tube within 15 minutes, and the time and amount of clot lysis were then noted at frequent intervals for 48 hours. Inasmuch as no differences were observed in the amount or time of lysis during the second 24-hour period, only the data from the first 24 hours will be presented.

A hematocrit was performed on an aliquot of the sample taken for fibrinolytic activity. The clot was removed in 24 or 48 hours, leaving in the tube variable amounts of residual cells and serum.

The value for the residual cells obtained by this method in several hundred determinations on normal individuals and patients without coagulation defects was less than 15 per cent of the total cells as calculated from the hematocrit for each determination. When 25 per cent or more of the total cells were found in this fraction, it was felt that fibrinolysis had occurred. The term "per cent lysis" is used to denote the per cent of the total red blood cells remaining in the tube after the clot is removed. Any reading below 20 per cent was not interpreted as being due to lysis. When complete lysis of the clot occurred (100 per cent), all the cells were in the residual fraction. Although the method is obviously semi-quantitative, it provided a practical tool for the estimation of the sum total of fibrinolytic activity induced by the SK in the patient's undiluted, whole blood, together with all its inhibitors and accelerators, and without the addition of any extraneous materials except those contained in Varidase

Serum inhibitor. Although by its usage "inhibitor" implies inhibition by a specific substance, in the tests performed the particular constituent in whole blood which is responsible for the inactivation of the streptococcal fibrinolytic system has not yet been identified. Furthermore, it was not clear which part or parts of the streptococcal fibrinolytic process were inhibited. The results of the inhibitor tests represent, therefore, a broad inhibitory phenomenon which may involve one or more factors.

The inhibitory effect described in this article as inhibitor was destroyed by heating at $56^{\circ} \mathrm{C}$. for 2 to 6 hours, unlike specific anti-SK antibody which is heat stable at $56^{\circ}$.

The inhibition test was performed as follows: Serial dilutions of a solution of SK were made so that amounts

- DC 200, Dow-Corning Corp., Midland, Mich.

7 The tip was made by winding five turns of Chromel-A wire, gauge 20 , on the tip of a 5 by $38 \mathrm{~mm}$. sheet metal screw. (Chromel-A, Haskins Mfg. Co., Detroit. Mich.) 


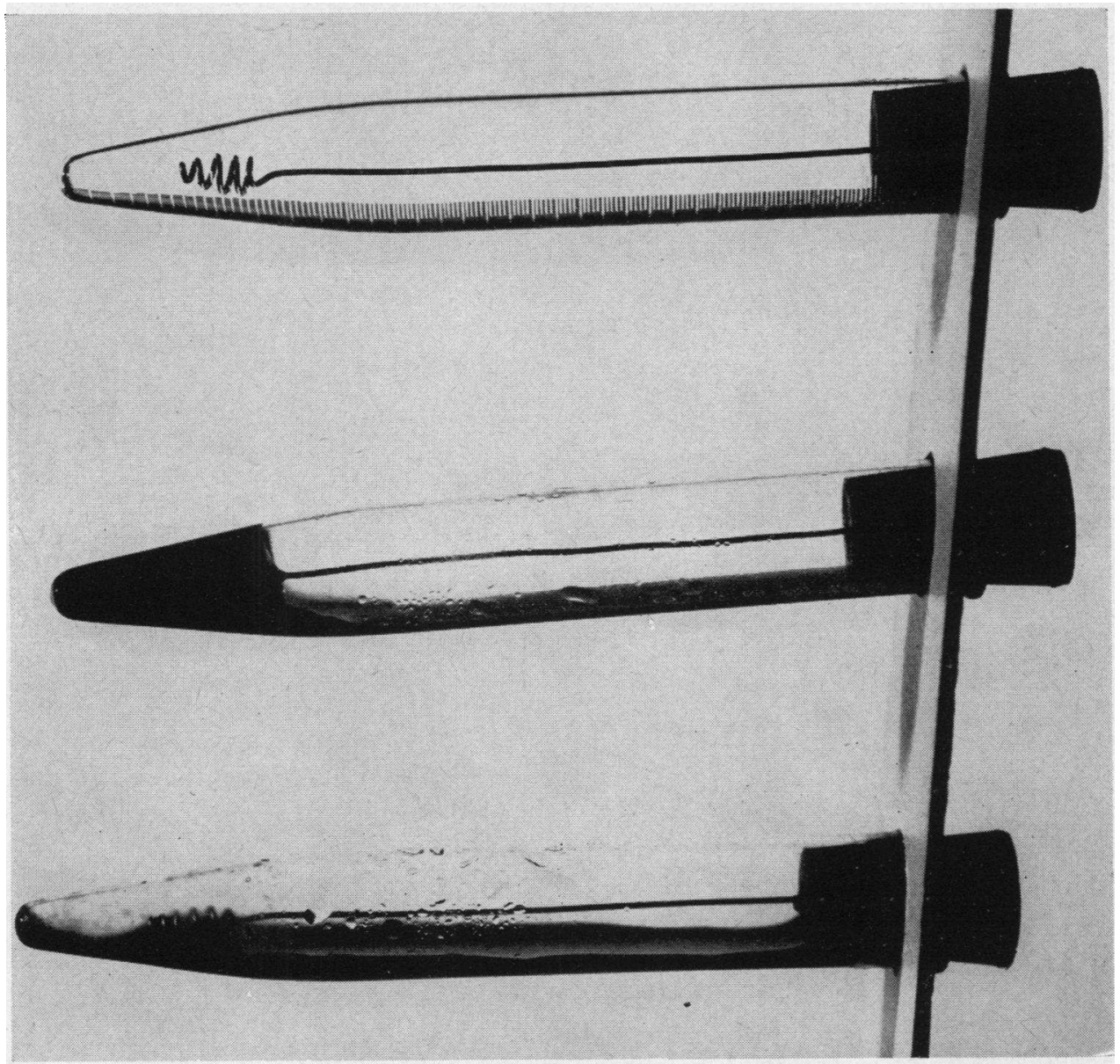

Fig. 1. Photographic Illustration of Tubes Employed in Fibrinolytic Tests of Patients' Blood (See Materials and Methods)

The upper centrifuge tube shows the configuration of the wire to which the clot adheres.

Two ml. of fresh whole blood was added to the centrifuge tube in the middle and two $\mathrm{ml}$. of fresh whole blood (containing SK) was added to the lower tube. The photographs were made after 2 hours incubation at $35^{\circ} \mathrm{C}$.

of SK varying from 2,000 units to 10 units were contained in $0.1 \mathrm{ml}$. of gelatin buffer. One tenth of one $\mathrm{ml}$. of each dilution was then dispensed into 12 by $75 \mathrm{~mm}$. test tubes. Whole blood, obtained by venepuncture with a siliconed syringe was placed immediately in a siliconed flask and $1.0 \mathrm{ml}$. of blood was added to each tube containing the amount of SK indicated in Figures 2 to 4 . After mixing by inversion, the time required for coagulation of the blood was recorded, as was the subsequent time required for complete lysis of the formed clot.

Because of the fact that the mechanism of inhibition is not yet clearly defined, the approximate amount of inhibitory effect found in each patient's blood (Fibrinolytic Profile) has been recorded in Figures 2 to 4 as + (low), ,+++++ (moderate), and ++++ (highest) rather than attempting to employ arbitrary quantitative units.

For purposes of comparison, inhibitor assays were also performed as previously described for plasmin or serum inhibitor (3), and trypsin inhibitor (4), respectively.

Plasminogen. The plasminogen was determined as previously described (3).

Fibrinogen. The method previously described for the determination of fibrinogen (3) was modified for use with the method of Ratnoff and Menzie (6). In the first method, the fibrin was brought down and washed by centrifugation in the cold, in the presence of trypsin inhibitor. In the modified method the plasma was diluted with saline-phosphate buffer at $\mathrm{pH} 6.4$ in an excess of calcium as described by Ware, Guest, and Seegers (7). Further, it was noted that the fibrin adhered more readily to the glass beads if $1 \mathrm{ml}$. of glass beads .0045 inch in diameter ${ }^{8}$ were added gradually during the entire clotting

\footnotetext{
${ }^{8}$ Minnesota Mining Corp., Minneapolis, Minn.
} 
process. The resulting clot was allowed to remain in the cold for 15 to 20 minutes and more glass beads were added if further clot formation occurred. After washing three times with the cold buffered saline and expressing the clot, the latter was digested in $2 \mathrm{ml}$. of $1 \mathrm{~N} \mathrm{NaOH}$, heated with agitation to $100^{\circ} \mathrm{C}$. for 15 minutes, and neutralized with $2 \mathrm{ml}$. of cold $1 \mathrm{~N} \mathrm{HCl}$. The "clottable tyrosine" was then determined (3). Unfortunately, it was not possible to centrifuge the initial sample of citrated whole blood in the cold, but the centrifugation was generally performed in about 10 minutes, after which the plasma was stored at $-20^{\circ} \mathrm{C}$.

Complement. The serum complement was determined by the method employed by Fischel, Pauli, and Lesh (8).

Other laboratory determinations. Conventional methods were used for the red blood cell count and hemoglobin, hematocrit, white blood cell count and differential, platelet count (Fonio's method), bleeding time (Duke methods), coagulation time (Lee-White method) (9), and prothrombin time (Quick method with Simplastin® 9) (10).

\section{RESULTS}

\section{Hematological Findings}

\section{Erythrocytes, hemoglobin, and hematocrit}

The determinations in 11 patients were performed before, during, and after the termination of the infusions. In no instance was any change observed in either RBC counts or amount of hemoglobin. Similarly, the hematocrit reading present before the infusions were begun did not alter during the period of instillation nor for 24 hours after its cessation.

9 Simplastin®, Chilcott Laboratories, Morris Plains, New Jersey.
Hemolysis was not observed, nor were immature red cells noted in the peripheral blood smear that might suggest a response to hemolysis.

\section{White blood cell and differential counts}

The counts were performed before the infusion was begun, at least two additional ones were made during the infusion and then at varying intervals for the next 24 to 36 hours following the cessation of the infusion.

The WBC count increased regularly and the rise averaged approximately $8,000 \mathrm{WBC}$, the highest number being reached approximately 20 hours after cessation of the infusions (Table I).

This increase was referable primarily to polymorphonuclear leucocytes and metamyelocyte II's ; differential counts performed at this time showed that these two cell types accounted for 80 per cent to 95 per cent of the total WBC count. The WBC count returned to the range of the pre-infusion range within the ensuing 24 hours. These results are in accord with the findings of patients receiving $\mathrm{SK}-\mathrm{SD}$ in extravascular areas for the eradication of hemorrhagic clots and purulent exudation (11).

\section{Platelets}

Since the limits of variation of the method employed in making platelet counts is considerable, the differences were of questionable significance. In four of the eight patients a decrease below the pre-injection count occurred during the period of infusion. In an analysis of 76 determinations

TABLE I

Variations in W.B.C. counts, platelet counts, and prothrombin times in association with intravenous infusions of SK

\begin{tabular}{|c|c|c|c|c|c|c|c|c|c|}
\hline \multirow[b]{3}{*}{ Patient } & \multicolumn{4}{|c|}{ WBC counts } & \multirow{2}{*}{\multicolumn{3}{|c|}{$\begin{array}{l}\text { Platelet counts } \\
\quad \text { (thousands) }\end{array}$}} & \multirow{2}{*}{\multicolumn{2}{|c|}{$\underset{(\text { seconds })}{\text { Prothrombin time }}$}} \\
\hline & \multirow[b]{2}{*}{$\begin{array}{l}\text { Pre-inf. } \\
\text { WBC }\end{array}$} & \multicolumn{2}{|c|}{ Highest count } & \multirow[b]{2}{*}{$\begin{array}{l}\text { Final } \\
\text { WBC }\end{array}$} & & & & & \\
\hline & & WBC & $\begin{array}{c}\text { Time* } \\
\text { (hours) }\end{array}$ & & Pre-inf. & $\begin{array}{c}\text { During inf. } \\
\text { (Lowest) }\end{array}$ & Post-inf. & Pre-inf. & $\begin{array}{c}\text { Post-inf. } \\
\text { (Highest) }\end{array}$ \\
\hline Wash. & 7,900 & 14,200 & 22 & 14,200 & 268 & 201 & 241 & 15. & 22 \\
\hline Petr. & 8,100 & 11,300 & 5 & 6,400 & 304 & 314 & 368 & 15.2 & 24.7 \\
\hline Bro. & 7,800 & 12,700 & 6 & 5,800 & 291 & 138 & 201 & 14.3 & 19. \\
\hline Bar. & 9,800 & 25,200 & 20 & 11,500 & 523 & 229 & 297 & 15.8 & 23.8 \\
\hline McD. & 14,700 & 24,800 & 20 & 11,500 & 520 & 506 & 360 & 12.9 & 18. \\
\hline Gill. & 5,700 & 30,350 & 20 & 8,600 & 201 & 200 & 201 & 17.2 & 24. \\
\hline Bai. & 6,500 & 16,100 & 25 & 9,700 & 464 & 452 & 401 & 14.2 & 14.2 \\
\hline Woll. & 10,700 & 12,400 & 1 & 8,300 & 401 & 390 & 555 & 14.9 & 33.4 \\
\hline Cynb. & 8,700 & 12,400 & 18 & 8,300 & - & - & - & 13.6 & 20.4 \\
\hline Gleas. & - & 13,400 & 12 & 8,300 & - & 332 & 371 & 18. & 20.5 \\
\hline
\end{tabular}

* Refers to post-infusion time (hours) when highest count was obtained.

$\dagger$ Done 24-48 hours, post-infusion. 
the changes ranged from an increase of 150,000 to a decrease of 294,000 and averaged 50,000 . In no instance did the platelet count fall below 115,000 . The fall in platelets was especially prominent in two patients, Bar and Bro, the decrease averaging 180,000 and 130,000 , respectively. It was of interest that these two patients received a dose of 100,000 units of SK, and responded with a relatively mild proteolytic system. However, the platelet count from patients who had larger doses of SK ( $M c D$ and $B a i)$ changed relatively little, while the platelet count on $W$ oll and Petr who had more proteolytic activity for a longer period of time actually increased. In the subsequent counts made on the following day, the number of platelets trended toward the preinfusion level (Table I). Since no significant changes in bleeding time or clotting time occurred, no abnormalities of blood coagulation that might have been referable to alterations in platelets were observed.

The coagulation time generally varied less than 2 to 3 minutes. The changes ranged from an increase of 3.5 minutes to a decrease of 7.5 minutes and averaged 1.5 minutes. The lowest coagulation time recorded was 6 minutes.

The bleeding time did not vary more than 1 to 2 minutes in any of the patients.

Although not related to the specific factors that influence tests for bleeding time or clotting time, some oozing of blood occurred in three patients during periods of active fibrinolysis, from the site of frequent stab wounds made in the finger pads for the various hematological tests. This bleeding from punctured cutaneous capillaries occurred only during periods when the circulating blood exhibited 100 per cent degree of fibrinolysis. Even though small clots formed in a normal manner at the sites of the punctures, they subsequently underwent lysis through the action of the fibrinolytic system contained within the coagulum as it formed. By the topical application of pressure, the oozing was controlled.

In a subsequent discussion consideration will be given to the possibilities of bleeding that might occur during periods of active fibrinolysis, in vivo.

\section{Effect of infusions on prothrombin time}

From the specific figures given in Table I, it may be seen that the prothrombin time was in- creased moderately following the intravenous infusions of SK and reached a maximum about 8 to 20 hours after cessation of the infusion. A return to normal levels occurred within the ensuing 12 to 24 hours.

Inasmuch as the prothrombin determinations were performed by the one-stage method which does not differentiate between prothrombin and the prothrombin accelerators, further studies are now in progress. Preliminary results of these determinations show a marked fall in Ac-globulin and a mild but definite reduction in the prothrombin. ${ }^{10}$ Sherry, Titchener, Gottesman, Wasserman, and Troll reported that Ac-globulin was depressed in dogs following intravenous infusions of SK (12).

In view of the fact that several increments of the blood have exhibited alterations as a result of the proteolytic activity, in vivo, in patients, Figures 5 and 6 - to be subsequently describedwill indicate the concomitant changes in prothrombin time together with plasminogen, fibrinogen, and complement in relation to the presence or absence of fibrinolytic activity.

\section{Urinary findings}

The abnormalities noted in repeated examination of urine consisted of: albuminuria irregularly present and slight, the appearance of a few cylindroids and granular casts, a moderate number of WBC, and occasionally 3 to $4 \mathrm{RBC}$ per high power field. The changes are similar to, but less marked than, those observed in patients receiving local injections of SK-SD, who had a pyrogenic response to the treatment (11). The abnormalities appeared a few hours after the infusion was begun. On the day following the termination of the infusion, the proteinuria and cylindruria, when present, had disappeared. Two days post-infusion the urinary findings returned to normal.

\section{Toxic effects}

In the present studies it was found that a febrile response of small but definite proportions was associated with the intravenous injection of

10 These determinations were performed in conjunction with Dr. W. H. Seegers and associates and will be subsequently reported as a separate study. 
TABLE II

Effect of intravenous infusions of SK on temperature and blood pressure. Patients were treated with Amidopyrine and Chlor-Trimeton (B)

\begin{tabular}{|c|c|c|c|c|c|c|c|c|}
\hline \multirow[b]{2}{*}{ Patient } & \multirow[b]{2}{*}{$\begin{array}{l}\text { Pre-inf. } \\
\text { temp. }\end{array}$} & \multirow[b]{2}{*}{$\begin{array}{l}\text { Dosage } \\
\text { of SK } \\
\text { (units) }\end{array}$} & \multicolumn{2}{|c|}{ Post-inf. temp. } & \multirow[b]{2}{*}{$\begin{array}{c}\text { Pre-inf. } \\
\text { B.P. } \\
\text { mm. } \dot{H}_{\boldsymbol{g}}\end{array}$} & \multicolumn{2}{|c|}{ Post-inf. B.P. } & \multirow[b]{2}{*}{$\begin{array}{l}\text { Time } \\
\text { return to } \\
\text { normal } \\
\text { (hours) }\end{array}$} \\
\hline & & & $\begin{array}{c}\text { Highest } \\
\left(F_{0}\right)\end{array}$ & $\begin{array}{c}\text { Occur- } \\
\text { rence } \\
\text { (hours) }\end{array}$ & & \multicolumn{2}{|c|}{$\begin{array}{l}\text { Lowest } \\
\qquad m m . H g\end{array}$} & \\
\hline $\begin{array}{l}\text { Wash. } \\
\text { Petr. } \\
\text { Bro. } \\
\text { Bar. } \\
\text { McD. } \\
\text { Gill. } \\
\text { Bai. } \\
\text { Woll.* } \\
\text { Cynb.* } \\
\text { Gleas.* }\end{array}$ & $\begin{array}{l}99.2 \\
98.6 \\
98.6 \\
97.6 \\
98.4 \\
98 . \\
98.6 \\
98.8 \\
98.8 \\
98.6\end{array}$ & $\begin{array}{r}100,000 \\
80,000 \\
100,000 \\
100,000 \\
125,000 \\
100,000 \\
120,000 \\
100,000 \\
100,000 \\
150,000\end{array}$ & $\begin{array}{r}100 . \\
100.2 \\
102 . \\
100.2 \\
99.6 \\
99.2 \\
99.6 \\
99.8 \\
100.2 \\
100 .\end{array}$ & $\begin{array}{r}10 \\
3 \\
4 \\
6 \\
8 \\
2 \\
6 \\
4^{*} \\
1^{*} \\
4^{*}\end{array}$ & $\begin{array}{l}120 / 78 \\
120 / 70 \\
126 / 94 \\
110 / 70 \\
102 / 70 \\
112 / 60 \\
132 / 70 \\
160 / 90 \\
110 / 64 \\
108 / 60\end{array}$ & $\begin{array}{r}98 / 74 \\
102 / 60 \\
74 / 54 \\
84 / 48 \\
66 / 50 \\
76 / 46 \\
92 / 60 \\
130 / 90 \\
96 / 66 \\
90 / 60\end{array}$ & $\begin{array}{l}10 \\
8 \\
24 \\
24 \\
12 \\
14 \\
20 \\
34^{*} \\
14^{*} \\
12^{*}\end{array}$ & $\begin{array}{l}24 \\
12 \\
48 \\
48 \\
48 \\
24 \\
48 \\
56 \\
30 \\
48\end{array}$ \\
\hline
\end{tabular}

* Patients Woll., Cymb., and Gleas. received 2, 3, and 2 repetitions of infusions. Time of recorded highest temp. and lowest B.P. were following 1st inf. No exacerbations of either Temp. or B.P. occurred with additional infusions.

Varidase containing as little as 5,000 units of SK. As the dosage of SK was raised, the pyrogenic effect became more marked. During the local use of SK-SD (Varidase ${ }^{\circledR}$ ) in the treatment of hemothorax and empyema (2), it was found that $0.1 \mathrm{gm}$. of amidopyrine given three times daily on the day prior to and the day of the local treatment modified substantially the febrile response that sometimes occurred as a result of the treatment. Inasmuch as a rise in temperature of 1 to $2^{\circ} \mathrm{F}$. occurred 6 to 8 hours after the intravenous infusion in those patients who received 5,000 units of SK (without amidopyrine), and because this febrile response took place even though the SK in the enzyme preparation was specifically neutralized by an excess of anti-SK antibody, the pyrogenic response was thought to be due to a non-specific type of foreign protein reaction. No leukopenic effects associated with the administration of amidopyrine have been observed as may be noted from the data on leucocyte counts contained in Table I.

The febrile response that occurred in $10 \mathrm{pa}-$ tients who received 80,000 to 150,000 units of SK while being treated with amidopyrine was mild (Table II). In patients untreated with amidopyrine, the rise in fever was observed to occur about 6 hours after local injections of SK-SD into the diseased thoracic area, the temperature reached its peak in about 24 hours and subsided during the following 24 to 48 hours.

In the present group of patients the rise of 1 to 2 degrees in temperature reached its peak at an earlier point and had returned to normal the following day. In no instance has the pyrogenic response presented a serious difficulty.

With doses of 80,000 to 150,000 units of SK utilized in this study the hypotensive effect of the infusions has been consistent in its occurrence and the drop in blood pressure has been significant. The blood pressure began to decrease within 3 to 6 hours after the termination of the infusion and the decline continued for the varying periods of hours indicated in Table III until the lowest point was reached. Within the next 4 to 8 hours the pressure began to rise and gradually and progressively increased to its pre-infusion level during the ensuing 24 to 48 hours. During the hypotensive period there were no symptoms of dizziness or impending shock.

The hypotensive effect was more evident in the changes in systolic pressure than in the diastolic pressure, the average drop in systolic readings was $31 \mathrm{~mm}$. $\mathrm{Hg}$ points and the diastolic was 14 mm. Hg.

The changes in blood pressure were not correlated with the presence or absence of fibrinolytic activity. For example, in patient Petr who exhibited 100 per cent lysis for 8 hours post-infusion and had 25 per cent lysis 48 hours post-infusion, the blood pressure fell about half as much as that in patient $B a i$ whose blood had no fibrinolytic activity during the total period of observation (Table II).

Furthermore, two patients (not included among the 11 of this report) with a high anti-SK anti- 
body were given 20 to 30,000 units of SK intravenously, without amidopyrine or Chlor-trimeton ; no fibrinolytic activity became evident but a significant fall in blood pressure occurred in each instance.

The chief subjective symptoms complained of by the patients were weakness, anorexia and occasionally nausea, which as a rule appeared during the night following the infusion. In a few instances vomiting occurred. The gastric symptoms when present, disappeared the following day.

\section{The Occurrence of Streptococcal Fibrinolysis, in Vivo, in Patients Receiving Intravenous Infusions of $S K$}

In the development of the study the earliest observations indicated that rapid intravenous injections performed in a few minutes time did not result in, in vivo, fibrinolysis even though the dosage of SK was above 50,000 units.

Consequently, continuous infusions were instituted according to the procedure that had proved effective in causing the liquefaction of intravascular clots in rabbits (3). As the dosage of SK was gradually increased, the duration of the continuous infusions was varied over a wide range from 2 to 12 hours in an effort to determine the rate of flow that would yield the most effective lytic system.

When the maximum dosage of SK so far administered was reached, with the toxic manifestations appropriately controlled, a plan of procedure was, with certain variations, followed in 11 consecutive patients. The complete data concerning them will be given in Figures 2 to 6 and Tables IV and V.

However, some of the preliminary findings may be briefly noted. As the dosage of SK was increased to 25,000 units and above, sporadic instances of fibrinolytic activity were evident in the circulating blood.

In Table III the dosage of SK and the duration of the infusion are given for a group of individuals whose blood taken, at the termination of the infusion for a single fibrinolytic test exhibited 100 per cent fibrinolysis. Other patients receiving similar dosages did not develop an active system. No other determinations of factors in the fibrinolytic system were made. Consequently the amount
TABLE III

Sporadic instances in which 100 per cent fibrinolysis was present in relation to dosage of $S K$ and duration of infusion *

\begin{tabular}{lcc}
\hline \hline Patient & $\begin{array}{c}\text { Dosage } \\
\text { of SK }\end{array}$ & $\begin{array}{c}\text { Duration of } \\
\text { infusion } \\
\text { (hours) }\end{array}$ \\
\hline Hank. & 25,000 & 6 \\
Who. & 30,000 & 8 \\
Ban. & 40,000 & 13 \\
Gre. & 65,000 & 10 \\
Fer. & 80,000 & 9 \\
Ben. & 80,000 & 6 \\
John. & 90,000 & 6 \\
Nel. & 95,000 & 6 \\
Son. & 100,000 & 6 \\
\hline
\end{tabular}

* Single sample of blood taken at end of infusion.

and significance of inhibitor, which will be subsequently shown to be of special importance, was not estimated.

The data indicate that an active fibrinolytic system may appear in isolated instances with the administration of varying amounts of SK considerably less than the maximum doses employed in this study provided the infusion is continued for several hours. In the patients cited in Table III no determinations were made of the time of appearance of active fibrinolysis during the course of the infusion nor the duration of activity following termination of the infusion.

\section{The Results of Detailed Studies of 11 Patients Re- ceiving 100,000 Units of $S K, \pm 25,000$ to 50,000 units}

The data to be described were derived from patients who either received continuous infusions during 4 to 5 hours or were given the total dose by intermittent infusions, with intervening intervals of 1 to 3 and $1 / 2$ hours between the infusions.

Among all the determinations that were made, the simplest and perhaps the one of greatest practical significance consisted of removing $2 \mathrm{ml}$. of blood, introducing the sample into the special type of centrifuge tube described in Materials and Methods, and incubating it in a water bath at $37.5^{\circ} \mathrm{C}$. The time of complete coagulation was noted and was followed by observing the occurrence of fibrinolysis during the subsequent 24 hours or longer. The results of the fibrinolytic tests varied from complete liquefaction, to partial lysis, to no lysis. Furthermore, it was observed that differences in the rate of lysis occurred even 
though the ultimate lysis was the same in different tubes. For example, the 100 per cent lysis in one test occurred in 30 minutes whereas in another test with another patient's blood, 100 per cent lysis required 8 to 10 hours incubation. The differences in rate of lysis is not included in the data presented, the results given in the Tables representing the final reading.

Another factor involved in both the rate and completeness of fibrinolysis is related to the quantity of fibrinogen available for transformation into fibrin. During the periods when the lytic system was active within the circulating blood, there was, Figures 5 and 6 , a reduction in the amount of circulating fibrinogen which was probably due to intravascular streptococcal fibrinogenolysis. Consequently, in tests, in vitro, the amount of fibrin formed from the decreased amount of circulating fibrinogen, is also less than normal, yielding a smaller amount of substrate to be lysed by the SK-plasmin system of the circulating blood.

It soon became evident that the degree of fibri- nolysis created in a patient's circulation bore a relation to the amount of inhibitor that was present prior to the beginning of the infusion. The pre-infusion test for "natural" inhibitor has been routinely performed in each patient and will be referred to as the Fibrinolytic Profile of an individual patient since it reflected to a considerable degree the fibrinolytic effects of the subsequent infusion of SK at the dosage employed.

\section{Results of inhibition tests}

Figure 2 contains a group of five patients that have been listed as exhibiting a low $(+)$ amount of inhibitor.

From Figure 2 it may be seen that in the tubes containing 100, 60, and 40 units of SK, the most rapid lysis occurred, ranging among the patients in this group from 8 to 12 minutes. With additional dilutions of SK employed (20 and 10 units) the lysis time slowed, but in all of them complete 100 per cent lysis occurred.

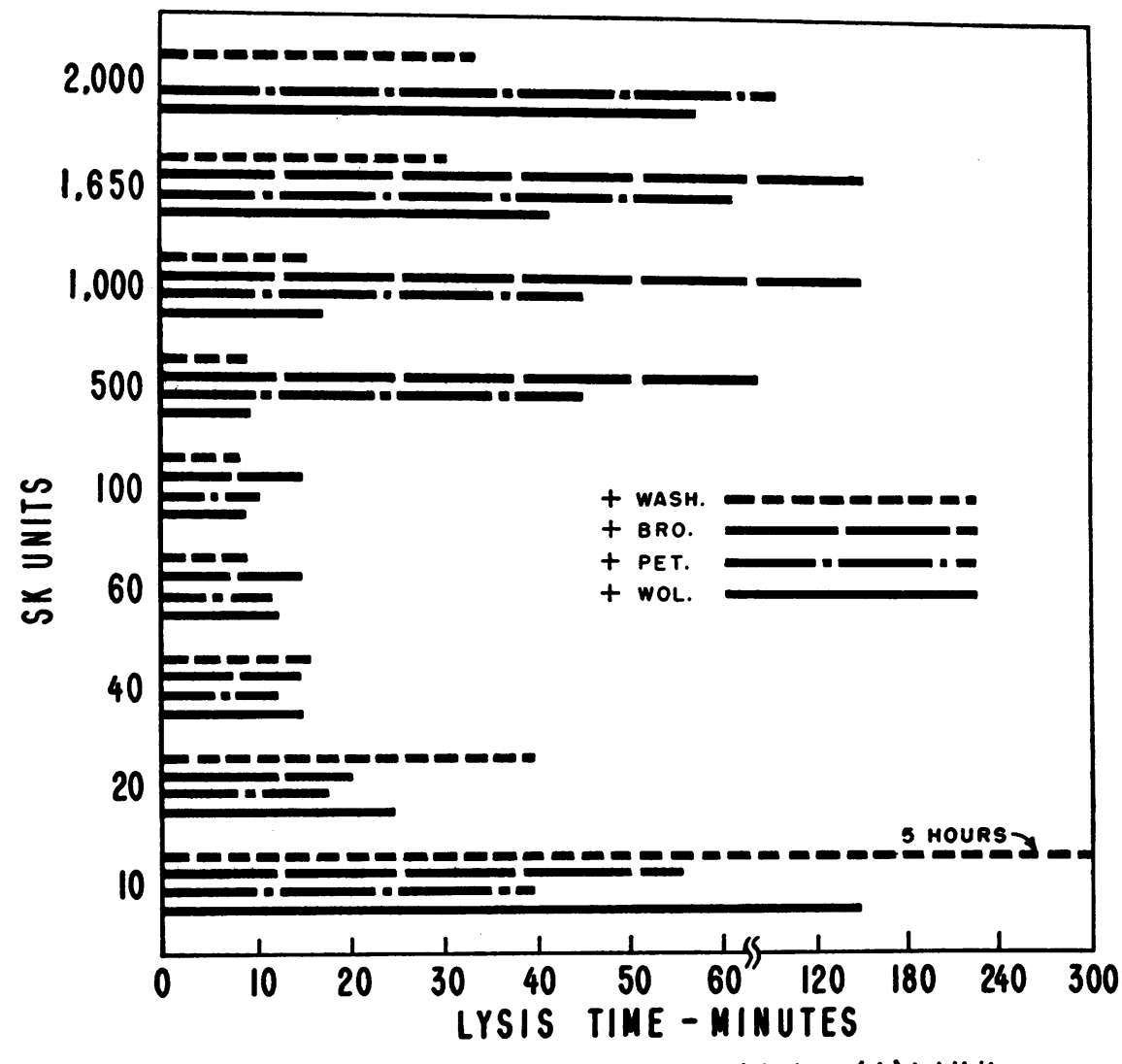

Fig 2 : Fibrinolytic Profile of Potients with Low $(+)$ Inhibitor. 


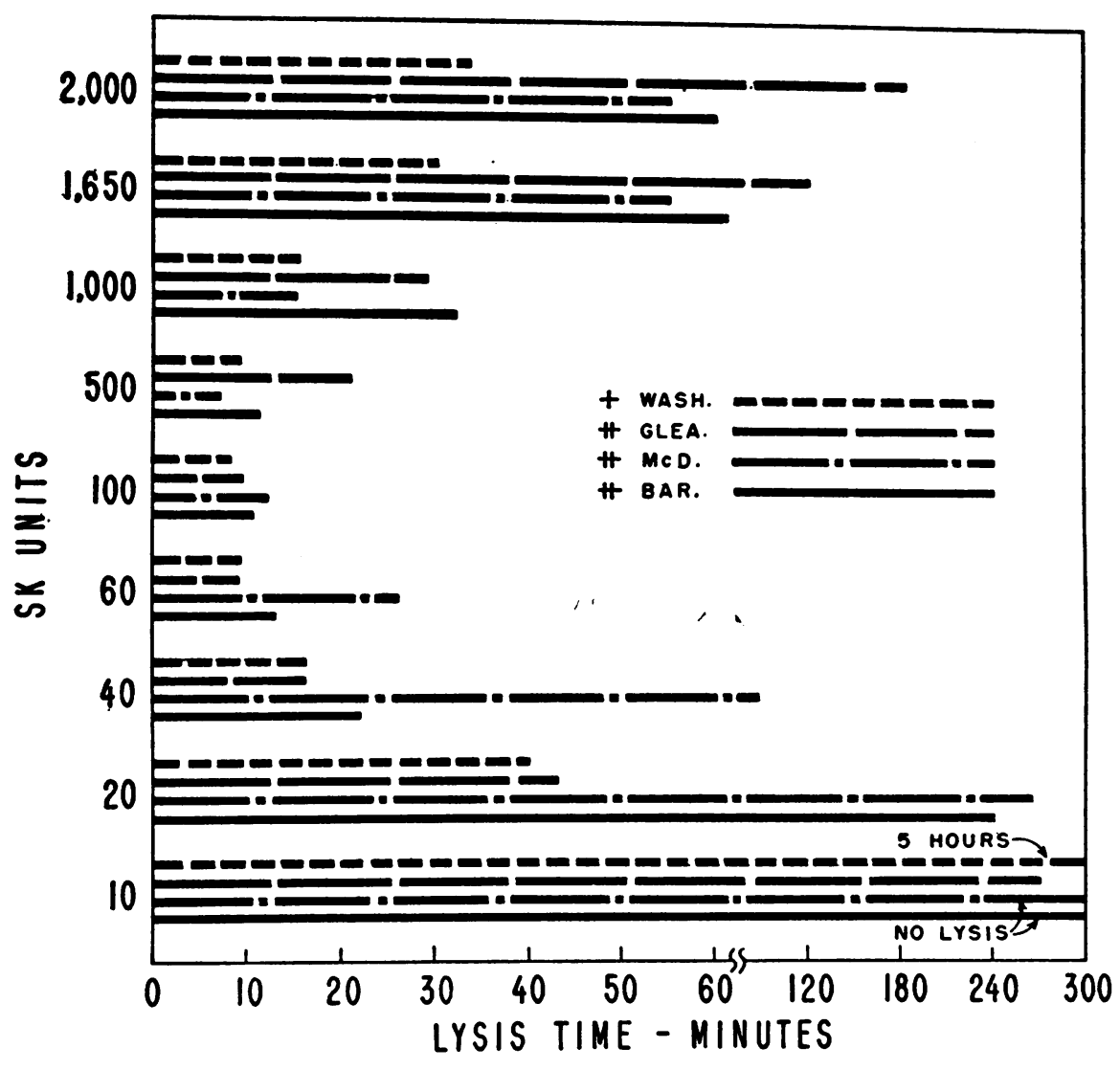

Fig. 3 : Fibrinolytic Profile of Potients with Moderate (t) Inhibitor.

As the amount of SK was increased above 500 units, a slowing of the lysis also occurred. The retarded rate of lysis observed in tests with larger amounts of SK has been interpreted as being due to an inhibitor of SK previously described (2) as being present in high concentrations of $\mathrm{SK}$, the inhibitor being present in the Varidase ${ }^{\circledR}$ preparation itself.

In Figure 3 are the Fibrinolytic Profiles of each of three patients who have been arbitrarily classified as having a somewhat larger amount of inhibitor than the patients included in Figure 1. The increased inhibition is particularly noted in the tubes containing 20 and 10 units of SK, but a slightly longer lysis time is also noted in all the tubes containing 40 units. The results with $\mathrm{Pa}$ tient Wash, one of the low inhibitor group, is reproduced again in Figure 2 with a dotted line in order to indicate the comparative difference between the two groups.

Figure 4 contains the Fibrinolytic Profile of two patients rated as having high $(++++)$ inhibitor. The blood of Patient Bai exhibited no lysis with any of the dilutions of SK and the blood of $\mathrm{Pa}$ tient Cous yielded only partial lysis in dilutions of SK that have proved in tests with other patients' blood to give maximum rates of liquefaction. The findings of Patient Wash, of the low inhibitor group, are also included in Figure 4 for purposes of comparison.

\section{Occurrence and Duration of Active Fibrinolysis in the Blood of Patients}

The findings recorded in Tables IV and V deal with the time of appearance of maximal fibrinolytic activity as it occurred during the course of the infusion and also the duration of activity after cessation of the infusion. Table IV concerns patients who had a single infusion; Table $\mathrm{V}$ concerns patients who had either two or three successive periods of infusion. 


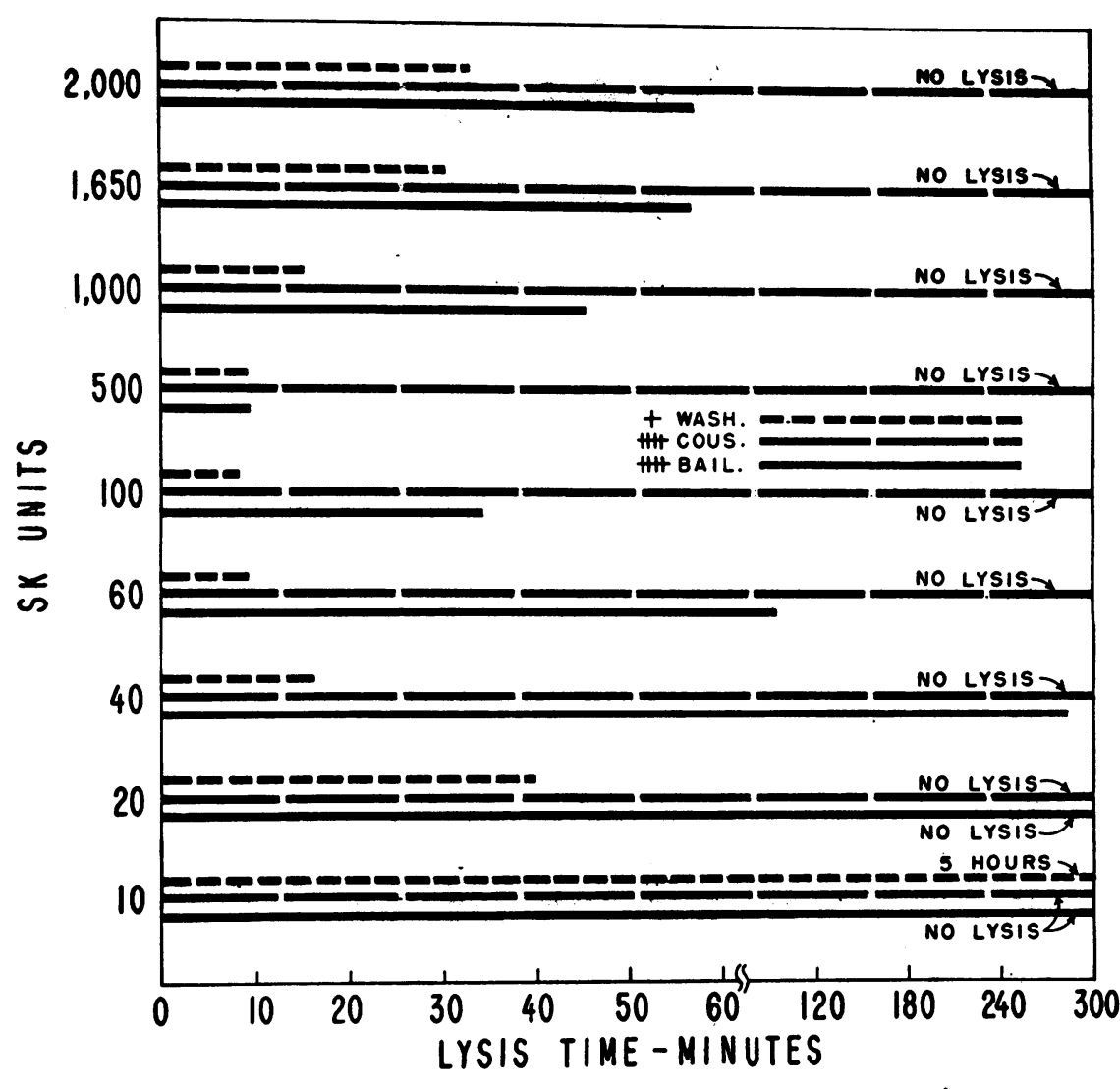

Fig. 4: Fibrinolytic Profile of Potients with High (+ftt) Inhibitor.

For Patient Wash (listed at the top of Table IV) it may be noted that the amount of inhibitor is classified in the low ( + ) group. As the tabulated data indicate, this patient's blood exhibited complete lysis after 50,000 units of SK had been introduced during the first 2 hours. When the infusion of 100,000 units had been completed in 4 hours, tests during the post-infusion period demonstrated that 100 per cent lysis persisted for 1 hour and was subsequently followed by a progressive decrease in the completeness of lysis of the test clots until, at the end of 24 hours, the patient's blood had returned to the near normal range.

From the data of the other six patients in Table IV, the relationship between the amount of inhibitor and the amount of SK required to initiate an active system are indicated as well as the effect of the larger amounts of inhibitor in shortening the post-infusion period of lytic activity.

In view of this finding, therefore, an additional group of four patients received repeated infusions with intervals of 1 to 3 hours between treatments. The results are given in Table V.

The first two patients of Table V, Woll and $C y n b$, had low amounts of inhibitor. In them the total dose of 100,000 units of SK was divided between 80,000 units and 75,000 units, respectively, at the first treatment, and 20,000 units and 25,000 units in the second period of infusion. The results suggest that the second dose, which was smaller than the first, represented a "booster" dose since the duration of post-infusion lysis (42 to 44 hours) was longer than in any of the patients of Table IV who received 100,000 units in a single infusion with the exception of Patient Petr of Table IV.

Further evidence for the effectiveness of a "booster" dose was obtained in three cases not represented here because of some incompleteness in the data. In two of these, the fibrinolysis induced by the initial dose of 50,000 to 75,000 units of SK was no longer evident 2 to 4 hours after the initial infusion. When, however, a smaller 


\section{TABLE IV}

\section{SINGLE INFUSIONS OF SK.}

OCCURRENGE OF FIBRINOLYSIS IN BLOOD OF PATIENTS DURING PERIOD OF INFUSION, AND DURATION OF ACTIVITY, FOLLOWING END OF INFUSION.

Its Correlation with Amount of Inhibitor.

\begin{tabular}{|c|c|c|c|c|c|c|c|c|c|c|c|c|}
\hline & & \multicolumn{3}{|c|}{ LYSIS DURING INFUSION } & \multicolumn{8}{|c|}{ LYSIS AFTER INFUSION } \\
\hline & & & & & $1-3 H$ & IOURS & $4-81$ & HOURS & $8-12$ & HOURS & $12-36$ & HOURS \\
\hline PATIENT & $\begin{array}{l}\text { * } \\
\text { AMOUNT Of } \\
\text { IMHIBITOR }\end{array}$ & $\begin{array}{c}\text { Lrsis, } \\
\%\end{array}$ & $\begin{array}{l}\text { TIME OF } \\
\text { MAX. LYSIS } \\
\text { (UNITS SK) }\end{array}$ & $\begin{array}{l}\text { TOTAL } \\
\text { UNITS SK } \\
\text { (TIME) }\end{array}$ & $\begin{array}{c}\text { LYSIS, } \\
\%\end{array}$ & \begin{tabular}{|l|} 
TIME OF \\
TEST, \\
HOU RS
\end{tabular} & LYsis, & $\begin{array}{c}\text { TIME OF } \\
\text { TEST, } \\
\text { HOURS }\end{array}$ & LYSIS, & $\begin{array}{l}\text { TIME OF } \\
\text { TEST, } \\
\text { HOUR'S }\end{array}$ & Lrsis, & $\begin{array}{l}\text { TIME OF } \\
\text { TEST, } \\
\text { HOURS }\end{array}$ \\
\hline WASH. & + & 100 & $\begin{array}{c}2 \text { HOURS } \\
(50,000 \text { U.) }\end{array}$ & $\begin{array}{l}100,000 \text { U. } \\
\text { (4 HOURS) }\end{array}$ & 100 & 1 & 50 & 4 & 40 & 9 & 20 & 24 \\
\hline PETR. & + & 100 & $\begin{array}{c}2 \text { HOURS } \\
(40,000 \text { U. })\end{array}$ & $\begin{array}{l}80,000 \text { U. } \\
\text { (4 HOURS) }\end{array}$ & 100 & 1 & 100 & 5 & 85 & 10 & 50 & 30 \\
\hline BRo. & + & 100 & $\begin{array}{c}3 \text { HOURS } \\
(60,000 \text { U. })\end{array}$ & $\begin{array}{l}100,000 \text { U. } \\
\text { (5 HOURS) }\end{array}$ & 100 & 1 & 30 & 5 & & & 18 & 17 \\
\hline BAR. & $+t$ & 100 & $\begin{array}{c}2 \text { HOURS } \\
(30,000 \text { U. })\end{array}$ & $\begin{array}{l}100,000 \text { U. } \\
\text { (4 HOURS) }\end{array}$ & 100 & 1 & 30 & 4 & 15 & 8 & & \\
\hline MeD. & $+t$ & 100 & $\begin{array}{c}4 \text { HOURS } \\
(125,000 \text { U. })\end{array}$ & $\begin{array}{l}125,000 \text { U. } \\
\text { (4 HOURS) }\end{array}$ & 100 & 3 & 10 & 8 & & & & \\
\hline GILL. & $++t$ & 45 & $\begin{array}{c}4 \text { HOURS } \\
(80,000 \text { U.) }\end{array}$ & $\begin{array}{l}100,000 \text { U. } \\
\text { (5 HOURS) }\end{array}$ & $<60$ & 2 & & & & & & \\
\hline BAI. & $++t+$ & 10 & & $\begin{array}{l}\text { 120, } 000 \text { U. } \\
\text { (4 HOURS) }\end{array}$ & 10 & 1 & & & & & & \\
\hline
\end{tabular}

* Eeo inhibiter, materiels end mothode

TABLE V

MULTIPLE INFUSIONS OF SK.

OCCURRENCE OF FIBRINOLYSIS IN BLOOD OF PATIENTS DURING PERIOD OF FIRST INFUSION. AND DURATION OF ACTIVITY FOLLOWING END OF LAST INFUSION. its Correlation with Amount of Inhibitor.

\begin{tabular}{|c|c|c|c|c|c|c|c|c|c|c|c|c|c|c|c|}
\hline & \multirow[b]{3}{*}{$\begin{array}{l}\text { * } \\
\text { AMOUNT OF } \\
\text { IMHIBITOR }\end{array}$} & \multirow[b]{3}{*}{ Infusion } & \multirow{2}{*}{\multicolumn{3}{|c|}{$\begin{array}{cl}\text { LYSIS } & \text { DURING } \\
\text { DIVIDED } & \text { INFUSIONS }\end{array}$}} & \multicolumn{10}{|c|}{ LYSIS AFTER INFUSION } \\
\hline & & & & & & \multicolumn{2}{|c|}{$1-3$ HOURS } & \multirow{2}{*}{$\frac{4-8}{\substack{\text { Lrsis, } \\
\%}}$} & \multirow{2}{*}{\begin{tabular}{|l|} 
HOURS \\
TIME OF \\
TEST, \\
HOURS
\end{tabular}} & \multicolumn{2}{|c|}{$8-20$ HOURS } & \multicolumn{2}{|c|}{ 20-48 HOURS } & \multicolumn{2}{|c|}{48.72 MOURS } \\
\hline patient & & & $\begin{array}{c}\text { Lrsis, } \\
x\end{array}$ & $\begin{array}{l}\text { TIME OF } \\
\text { MAX. LYSIS } \\
\text { (UNITS SK) }\end{array}$ & $\begin{array}{l}\text { TOTAL } \\
\text { UNITS SK } \\
\text { (TIME) }\end{array}$ & $\begin{array}{c}\text { Lrsis } \\
\%\end{array}$ & $\begin{array}{l}\text { TIME OF } \\
\text { TEST, } \\
\text { HOURS }\end{array}$ & & & \begin{tabular}{|c|} 
Lrsis, \\
$x$
\end{tabular} & \begin{tabular}{|l|} 
TIME OF \\
TEST, \\
HOURS
\end{tabular} & $\begin{array}{c}\text { Lrsis, } \\
\%\end{array}$ & $\begin{array}{l}\text { TIME OF } \\
\text { TEST, } \\
\text { HOURS }\end{array}$ & Lrsis & $\begin{array}{l}\text { TIME OF } \\
\text { TEST, } \\
\text { HOURS }\end{array}$ \\
\hline \multirow{2}{*}{ wOLL. } & \multirow{2}{*}{+} & 1st & 100 & $\begin{array}{c}2 \text { HOURS } \\
(40,000 \text { U.) }\end{array}$ & $\begin{array}{l}80,000 \text { U. } \\
\text { (4 HOURS) }\end{array}$ & & & & & & & & & & \\
\hline & & 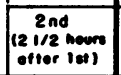 & 100 & & $\begin{array}{c}20,000 \text { U. } \\
(1 / 2 \text { HOUR })\end{array}$ & 100 & $11 / 2$ & 100 & 5 & 80 & 12 & 60 & 42 & 15 & 72 \\
\hline \multirow[b]{2}{*}{ crne. } & \multirow[b]{2}{*}{+} & $1 \%$ & 100 & $\begin{array}{c}2 \text { HOURS } \\
(50,000 \text { U. })\end{array}$ & $\begin{array}{l}: 5,000 \text { U. } \\
\text { (3 HOURS) }\end{array}$ & 100 & 1 & 70 & 2 & & & & & & \\
\hline & & \begin{tabular}{|l|}
2 nd \\
13 1/2 nown \\
offor lel \\
\end{tabular} & 100 & & $\begin{array}{l}25,000 \text { U. } \\
\text { (1 HOUR) }\end{array}$ & 100 & 1 & 45 & 4 & 25 & 20 & 25 & 44 & 10 & 68 \\
\hline \multirow{3}{*}{ GLEAS. } & \multirow{3}{*}{$+t$} & 1 st & 25 & $\begin{array}{c}5 \text { HOURS } \\
(100,000 \text { U. })\end{array}$ & $\begin{array}{l}100,000 \text { U. } \\
\text { (5 HOURS) }\end{array}$ & 25 & 1 & & & & & & & & \\
\hline & & 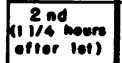 & & & $\begin{array}{c}25,000 \text { U. } \\
\text { (3/4 HOURS) }\end{array}$ & 100 & 1 & & & & & & & & \\
\hline & & \begin{tabular}{|c|}
$3 r d$ \\
$131 / 2$ nound \\
oflor 2 nod
\end{tabular} & & & $\begin{array}{l}25,000 \text { U. } \\
\text { (1 HOUR) }\end{array}$ & 100 & $1 / 4$ & & & 20 & 14 & 35 & 20 & 30 & 40 \\
\hline \multirow{2}{*}{ cous. } & \multirow{2}{*}{++++} & 1 in & o & & $\begin{array}{l}100,000 \text { U. } \\
\text { (12 HOURS) }\end{array}$ & & & & & & & & & & \\
\hline & & $\begin{array}{l}2 \text { nd } \\
(12 \text { nours } \\
\text { offer lot) }\end{array}$ & o & & $\begin{array}{l}\text { So, 000 U. } \\
\text { (5 MOURS) }\end{array}$ & 0 & & 0 & & 0 & & $\mathbf{0}$ & & ○ & \\
\hline
\end{tabular}

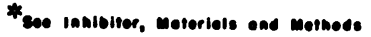


dose of 12,000 to 25,000 units of SK was subsequently given, 100 per cent lysis occurred for the ensuing 6 to 10 hours. In the third case, a strongly proteolytic system (ranging from 50 to 100 per cent lysis) was maintained in vivo for 72 hours by a total of 57,000 units of SK given in an initial dose of 25,000 units, followed over the three-day period by three divided doses of approximately 10,000 units each.

The last patient of Table V, Patient Cous had such a high amount of inhibitor that even a total of 150,000 units given in two infusions failed to create any fibrinolytic activity.

\section{Effect of Infusion of SK on Fibrinogen, Plas- minogen and Complement in Circulating Blood}

In the previous report (1) it was demonstrated that substantial decreases occurred in the fibrinogen content of inflammatory pleuritic effusions following the injection into the pleural cavity of SK-SD. Furthermore, that SK acts upon fibrinogen as well as fibrin, in vitro, has been demonstrated (13). In the studies of intravenous injections of SK into rabbits (3) moderate decreases in the circulating fibrinogen were noted. The decrease proceeded at a slow rate in spite of the constant infusion and the presence of an active fibrinolytic system. The results suggested that the rate of fibrinogenolysis, in vivo, may be slower than in vitro, or that the reformation of fibrinogen by rabbits may be sufficiently rapid to parallel closely the slow rate of lysis. The latter possibility was further suggested by the finding that on the day following the infusion in rabbits the fibrinogen rose to higher levels than that noted prior to the infusion, indicating the active synthesis of fibrinogen.

Concerning plasminogen (referred to in the previous article (1) as activatable fibrin-lysing system), it was shown in inflammatory pleural effusions that this plasma factor decreased rapidly after the intrapleural injection of SK-SD although the blood level remained unchanged. In rabbits following the intravenous instillation of $1,800,000$ units of SK for 24 hours, it was found that the level of plasminogen progressively decreased from 300 units to 30 units per $\mathrm{ml}$. at the end of the infusion.
Pillemer, Ratnoff, Blum, and Lepow have reported (14) that SK added to human serum, followed by the development of plasmin activity, destroyed complement, in vitro. The SK-plasmin preparations caused inactivation, particularly of complement components $\mathrm{C} 2$ and $\mathrm{C} 4$, and also varying amounts of $\mathrm{Cl}$.

Samples of serum derived from the serial bleedings of patients before, during and after the infusions of SK, have been tested for their content in complement. ${ }^{11}$

In the subsequent Figures 5 and 6 concomitant alterations in prothrombin time, complement, plasminogen, and "clottable tyrosine" (fibrinogen) are correlated with the fibrinolytic activity created in the general circulation of the patients by the intravenous infusions of SK. Figure 5 contains the findings in a patient with low $(+)$ inhibitor; Figure 6 those of a patient with high $(++++)$ inhibitor.

With respect to the increments of the blood directly involved in streptococcal fibrinolysis, there was a beginning decrease in both fibrinogen and plasminogen at about the time that 100 per cent fibrinolysis was attained and the point of greatest decrease occurred after maximum lytic activity had been sustained for several hours (Figure 5, patient with low inhibitor; Figure 6, patient with high inhibitor). In the post-infusion period the values for these two substances gradually returned to normal as the fibrinolytic activity disappeared.

The sharp drop in complement resulting from the infusion is also evident, as is also a moderate prolongation of the prothrombin time during the post-infusion period (Figure 5).

In Patient $B a i$ with the highest amount of inhibitor and in whom no active fibrinolytic system was developed, no quantitative changes occurred in "clottable tyrosine" (fibrinogen), and the prothrombin time remained unchanged throughout and after the infusion (Figure 6). However, a definite decrease occurred in both complement and

\footnotetext{
11 The quantitative determinations of complement reported in this article were performed in the laboratory of Dr. David P. Earle and under his direction. The tests for complement in our patients were done in connection with other studies being conducted by Dr. Earle on changes in complement in patients with different diseases. The findings in the SK treated patients are included with the permission of Dr. Earle.
} 
plasminogen, in spite of the fact that no activity of the fibrinolytic system was measurable.

Among the other patients the pattern of the changes as demonstrated in Patient Wash (Figure
5) with low inhibitor and in Patient Bai (Figure

6) with high inhibitor, have been relatively uniform and may be summarized as follows: The extent to which fibrinogenolysis occurred paral-

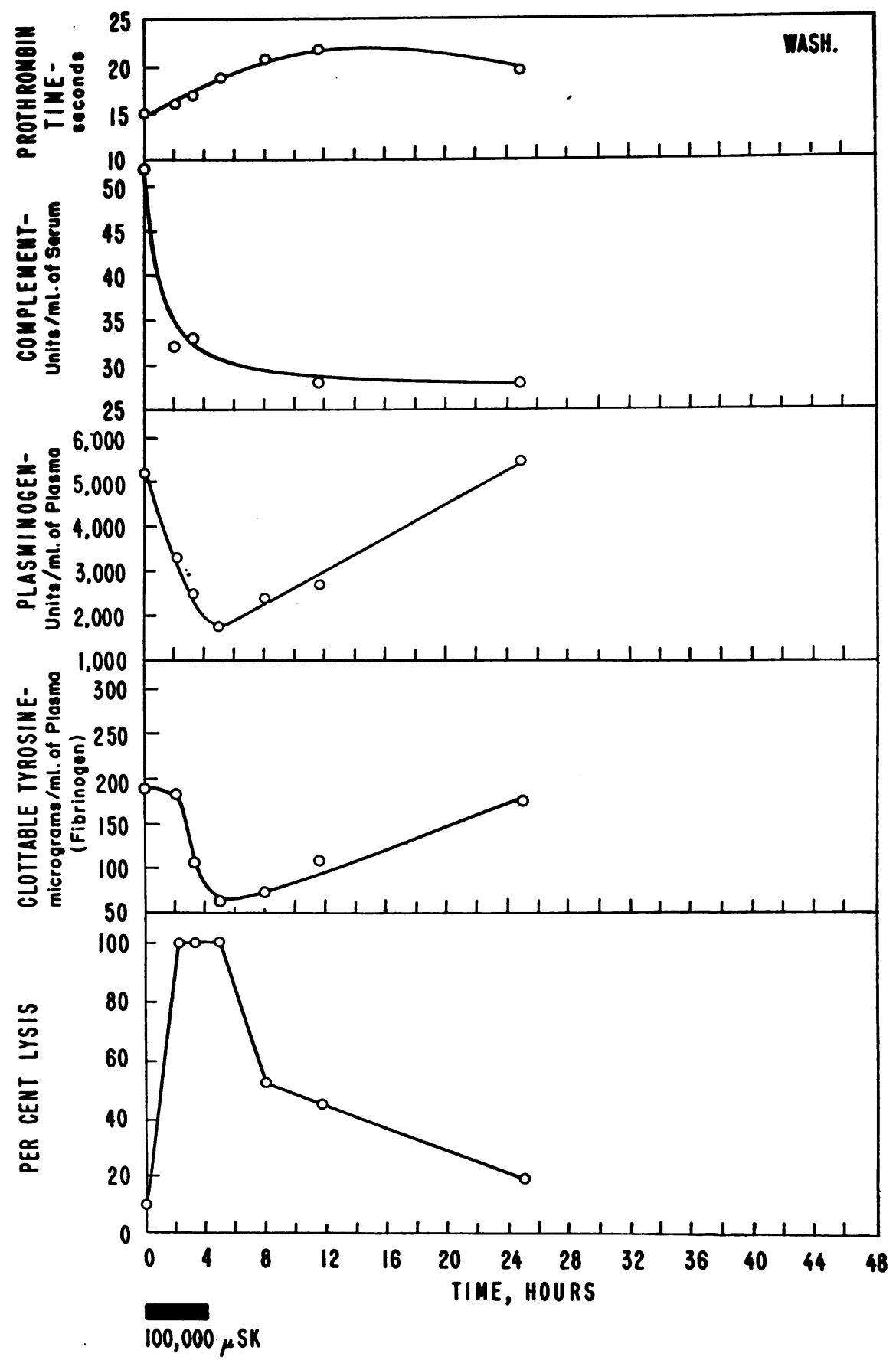

Fig. 5. Effect on Certain Blood Components of 100,000 Units of SK Injected by Continuous Intrayenous Infusion in 4 Hours in a Patient with Low IN HIBITOR 
leled the degree of activity of the fibrinolytic system. Variations in the prolongation of prothrombin time, which were never great, also conformed to the degree of activity of the lytic system.
However, as noted in Figure 6 substantial decreases in plasminogen and complement occurred irrespective of whether or not active fibrinolysis developed as a result of the infusions of SK.

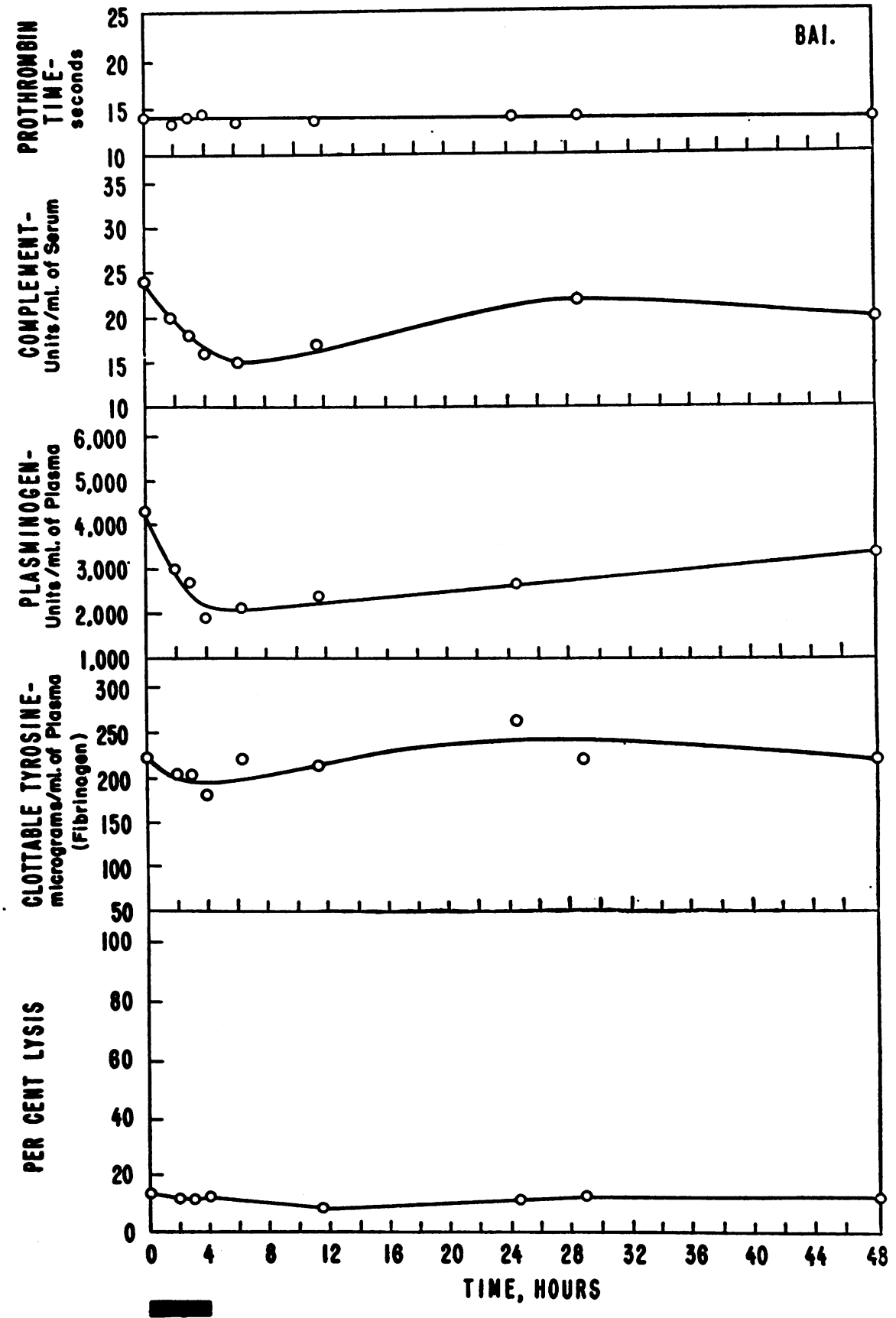

120,000 \&SK

Fig. 6. Efrect on Certann Blood Components of 120,000 Units of SK Injected by Continuous Intravenous Infusion in 4 Hours in a Patient with High INHIBITOR 
In the light of present knowledge it would be premature to attempt to interpret the findings just described except to point out the somewhat unique spectrum of proteolysis that is associated with the intravenous infusion of SK into patients in the amounts employed in this study. It should also be noted that Varidase ${ }^{\circledR}$ contains substances both known and unknown, other than SK. Consequently, although it seems highly probable that the SK system accounts for the results just described, the final correct interpretation must await the identification of all the moieties contained in Varidase ${ }^{\circledR}$.

\section{DISCUSSION}

The extent to which the pyrogenic and hypotensive effects of the infusions are referable either to SK itself or to the products of enzymatic action, or to one or more of diverse substances that are contained in Varidase ${ }^{\circledR}$ cannot be finally evaluated until more highly purified preparations of SK become available. Indirect evidence suggests that the impurities in Varidase ${ }^{(8)}$ are chiefly responsible for the foreign protein type of reactions. Bradley, Chasis, Goldring, and Smith (15) in studies, chiefly of hypertensive patients during pyrogenic reactions provoked by typhoid vaccine, observed that even though the administration of amidopyrine obviated the febrile reaction, hypotension developed. They ascribed the lowering of blood pressure, in part, to vasodilatation.

It should be re-emphasized that only two lots of Varidase ${ }^{8}$ Nos. 96A and 333A-were employed in this study although several others were investigated preliminarily, and that the toxicity of each lot was investigated independently of the other by initiating the use of each with small intravenous doses and increasing gradually. Even though these and other lots have been tested by Lederle Laboratories for pyrogenicity in rabbits, no clear-cut relationship has been evident between the effects on rabbits and man. In the present state of knowledge, therefore, it would not appear advisable to inject intravenously effective, fibrinolysis-producing amounts of indiscriminate lots of SK-25,000 units and upward-for therapeutic purposes without first determining the specific effects of individual lots.

The active fibrinolysis created within the circulating blood exhibited features which indicate that it may serve as an effective method of therapy in the treatment of intravascular occlusions of fibrinous composition. It is also apparent from the data that a considerable amount of additional information is required before the practical therapeutic use of infusions of SK may be safely conducted and properly controlled.

One potential danger, which has not yet been encountered, but which warrents special comment, is the possibility of the occurrence of extravascular hemorrhage during the period when the active fibrinolytic system is present in the circulation.

In the text of this report attention was called to the fact that spontaneous bleeding occurred at the sites of the fresh stab wounds made in the pads of the fingers to obtain blood counts, although standard tests of bleeding and clotting time were normal.

In the previous studies in rabbits (3) it was observed that when indwelling catheters were placed in the bladder to obtain specimens of urine, local excessive bleeding occurred if the bladder mucosa was traumatized during the period when fibrinolysis was active within the general circulation. Studies are now in progress which are directed toward developing a method by which the activity of the fibrinolytic system may be promptly terminated if necessary.

Some of the other difficulties to be overcome may be briefly cited. The exact nature and modes of action of the "naturally" occurring inhibitor or inhibitors are not yet clearly defined, particularly in relation to the streptococcal fibrinolytic system. Because of its heat lability the inhibitor is not to be confused with the specific heat stable anti-SK antibody, which results from hemolytic streptococcal infections.

In view of the relative frequency of the occurrence of the inhibitory phenomenon in varying amounts in patients, a method of "neutralizing" the inhibition of lytic activity either by increasing the dosage of SK, or by altering the rate of infusion, or by means other than those involving the dosage of SK would be useful.

Another as yet unexplained part of the in vivo fibrinolytic phenomenon is found in the differences in the rate of lysis. For example, in different tests performed with samples of blood from different patients, 100 per cent lysis occurred in each of the tests but the time required for com- 
pletion varied from 30 minutes to 10 hours. Similar variations in rate were observed in tests in which varying degrees of partial lysis occurred. since it is not yet established in patients what degree or rate of fibrinolysis is most advantageous in abolishing pathologically induced intravascular fibrin clots, the significance of the variations in terms of practical effective therapy requires more definition.

Several investigators have injected intravenously a preformed plasmin, activated by SK in vitro, into animals, and observed fibrinolysis, in vivo.

Cliffton, Cannamela, and Grossi (16) injected a solution containing SK activated human plasminogen into dogs and rabbits and noted a marked increase in the lytic activity of the blood of both animal species. Subsequently the same authors (17) reported on the successful liquefaction by SK-human plasmin of thrombi produced in the femoral veins of dogs. There was a marked increase in the lytic activity of the blood in the general circulation of the animals.

Sherry has elucidated several features of SK fibrinolytic activity which have a bearing on the use, in vivo, of SK. This investigator has recently reported that $\mathrm{SK}$ in the presence of small amounts of the human serum factor (plasminogen or SKplasmin) activates bovine or canine plasminogen which exists as a contaminant of the preparations of animal fibrinogens employed in tests performed, in vitro (18). According to these findings, therefore, when SK-human plasmin is injected intravenously into dogs, the high degree of fibrinolytic activity developed within the circulating blood of the dog is referable to a considerable degree to the activation of the dog's own system rather than to the direct action of the SK-human plasmin.

In other articles, Sherry, Titchener, Gottesman, Wasserman, and Troll $(12,19)$ have reported upon the enzymatic dissolution of experimental arterial thrombi in dogs. The authors reported that the injection of moderately small amounts of SK plus partially purified human plasminogen preparations effected rapid activation of the dogs fibrinolytic system with lysis of the arterial clots together with a significant increase in broad proteolytic activity within the circulating blood. Injections of SK alone intravenously in the dogs also promoted clot dissolution but the required amount of SK was greater than that contained in the SK-human plasmin preparation. Minor increases in circulating proteolytic activity in association with marked fibrinolytic activity were demonstrable when SK alone was employed in dogs.

Extensive studies have not been performed to delineate the extent of the range of proteolytic activity occurring in the general circulation of the patients receiving SK. However, the findings suggest that with the dosage of SK employed in the patients, the degree of proteolysis occupied a position intermediate between the "burst" of proteolysis obtained by injections of SK-human plasmin into dogs and the less extensive changes resulting from injections of SK alone into dogs (12, 19).

\section{SUM MARY}

Streptokinase (contained in Varidase ${ }^{(\circledast)}$ ), in amounts ranging from 75,000 to 150,000 units, has been introduced intravenously into patients, 11 of whom were studied in detail as described in this article. Both continuous and intermittent infusions of 4 to 5 hour duration have been used.

The hematological effects have consisted chiefly of polymorphonuclear leucocytosis, and some irregular variations in platelet counts with no appreciable alteration of the clotting time or bleeding time. Moderate prolongations of prothrombin time occurred following the creation of active fibrinolytic systems in patients with low titres of naturally occurring inhibitor. No alterations in prothrombin time were observed in patients with high inhibitor in whom active fibrinolysis did not develop.

The principal toxic manifestations were pyrogenic reactions which were well controlled by the administration of amidopyrine, and hypotensive effects for which Chlor-trimeton Maleate was given. The decreases in blood pressure were usually maximal 8 to 24 hours after termination of the infusion and usually returned to normal during the following 24 hours. The systolic blood pressure was affected more than the diastolic. No symptoms attended the lowering of the blood pressure.

An active fibrinolytic system was developed in six of the seven patients who received continuous infusions for 4 to 5 hours, and in five of the seven, 100 per cent fibrinolytic activity was at- 
tained. After termination of the infusion, lytic activity remained 100 per cent for 1 to 3 hours and then decreased with varying degrees of partial activity persisting for 4 to 30 hours depending to a considerable degree on the amount of "natural inhibitor" present in the individual patient's blood.

Repeated infusions (two times in three, and three times in one patient) were given in which the 2nd or 3rd infusion represented a "booster" dose. The degree and duration of fibrinolytic activity was greater and persisted longer in three of the four patients of this group than in those receiving a single infusion even though the total amount of SK was essentially the same.

When an active lytic system was developed in patients with low inhibitor concomitant decreases occurred in fibrinogen, plasminogen, and complement. When no lytic activity occurred in patients with high inhibitor, no fibrinogenolysis or fibrinolysis occurred, but there were significant but lesser decreases in both plasminogen and complement.

The potential hazards present during the periods of active fibrinolysis have been pointed out, and some of the conspicuous problems that remained to be studied have been indicated.

\section{REFERENCES 12}

1. Tillett, W. S., and Sherry, S., The effect in patients of streptococcal fibrinolysin (streptokinase) and streptococcal desoxyribonuclease on fibrinous, purulent, and sanguinous pleural exudations. J. Clin. Invest., 1949, 28, 173.

2. Sherry, S., Tillett, W. S., and Read, C. T., The use of streptokinase-streptodornase in the treatment of hemothorax. J. Thoracic Surg., 1950, 20, 393.

3. Johnson, A. J., and Tillett, W. S., The lysis in rabbits of intravascular blood clots by the streptococcal fibrinolytic system (streptokinase). J. Exper. Med., 1952, 95, 449.

4. Christensen, L. R., Methods for measuring the activity of components of the streptococcal fibrinolytic system, and streptococcal desoxyribonuclease. J. Clin. Invest., 1949, 28, 163.

12 For comprehensive review of recent articles on clinical use of Varidase (streptokinase-streptodornase), see bibliography contained in: "Recent advances in Varidase therapy" distributed by Lederle Laboratories Division, American Cyanamid Co., 30 Rockefeller Plaza, New York 20, N. Y.
5. Yonkman, F. F., Chess, D., Mathieson, D., and Hansen, N., Pharmacodynamic studies of a new antihistamine agent, $\mathrm{N}^{\prime}$-pyridyl- $\mathrm{N}^{\prime}$ benzyl- $\mathrm{N}$-dimethylethylene diamine $\mathrm{HCl}$, pyribenzamene $\mathrm{HCl}$. J. Pharmacol. \& Exper. Therap., 1946, 87, 256.

6. Ratnoff, O. D., and Menzie, C., A new method for the determination of fibrinogen in small samples of plasma. J. Lab. \& Clin. Med., 1951, 37, 316.

7. Ware, A. G., Guest, M. M., and Seegers, W. H., Fibrinogen: with special reference to its preparation and certain properties of the product. Arch. Biochem., 1947, 13, 231.

8. Fischel, E. E., Pauli, R. H., and Lesh, J., Serological studies in rheumatic fever. II. Serum complement in the rheumatic state. J. Clin. Invest., 1949, 28, 1172.

9. Wintrobe, M. M., Clinical Hematology. Philadelphia, Lea and Febiger, ed. 3, 1951.

10. Shapiro, S., Weiner, M., Luddecke, H. F., Kroc, R. L., and White, E. J., A simply prepared, standardized, and relatively stable thromboplastin extract for estimation of prothrombin time. Am. Heart J., 1950, 40, 766.

11. Hubbard, W. N., Jr., The systemic toxic responses of patients to treatment with streptokinase streptodornase (SK-SD). J. Clin. Invest., 1951, 30, 1171.

12. Sherry, S., Titchener, A., Gottesman, L., Wasserman, $P$., and Troll, W., The enzymatic dissolution of experimental arterial thrombi in the dog by trypsin, chymotrypsin, and plasminogen activators. J. Clin. Invest., 1954, 33, 1303.

13. Garner, R. L., and Tillett, W. S., Biochemical studies on the fibrinolytic activity of hemolytic streptococci. II. Nature of the reaction. J. Exper. Med., 1934, 60, 255.

14. Pillemer, L., Ratnoff, O. D., Blum, L., and Lepow, I. H., The inactivation of complement and its components by plasmin. J. Exper. Med., 1953, 97, 573.

15. Bradley, S. E., Chasis, H., Goldring, W., and Smith, H. W., Hemodynamic alterations in normotensive and hypertensive subjects during the pyrogenic reaction. J. Clin. Invest., 1945, 24, 749.

16. Cliffton, E. E., Cannamela, D. A., and Grossi, C. E., In vivo studies of human plasmin. Intravenous injection in dogs and rabbits. J. Applied Physiol., 1953, 6, 143.

17. Cliffton, E. E., Grossi, C. E., and Cannamela, D., Lysis of thrombi produced by sodium morrhuate in the femoral vein of dogs by human plasmin (fibrinolysin). Ann. Surg., 1954, 139, 52.

18. Sherry, S., The fibrinolytic activity of streptokinase activated human plasmin. J. Clin. Invest., 1954, 33, 1054.

19. Sherry, S., Titchener, A., Gottesman, L., Wasserman, P., and Troll, W., The enzymatic dissolution of intravascular clots. J. Lab. \& Clin. Med., 1953, 42, 952. (Abst.) 